\title{
Identification of a Loss-of-Function Mutation in the Context of Glutaminase Deficiency and Neonatal Epileptic Encephalopathy
}

Lynne Rumping, MD; Benjamin Büttner; Oliver Maier, MD; Holger Rehmann, PhD; Maarten Lequin, MD, PhD; Jan-Ulrich Schlump, MD; Bernhard Schmitt, MD; Birgit Schiebergen-Bronkhorst, BSc;

Hubertus C. M. T. Prinsen, PhD; Michele Losa, MD; Ralph Fingerhut, PhD, FAMH; Johannes R. Lemke, MD;

Fried J. T. Zwartkruis, PhD; Roderick H. J. Houwen, MD; Judith J. M. Jans, PhD; Nanda M. Verhoeven-Duif, PhD; Peter M. van Hasselt, MD, PhD; Rami Jamra, MD

IMPORTANCE The identification and understanding of the monogenic causes of neurodevelopmental disorders are of high importance for personalized treatment and genetic counseling.

OBJECTIVE To identify and characterize novel genes for a specific neurodevelopmental disorder characterized by refractory seizures, respiratory failure, brain abnormalities, and death in the neonatal period; describe the outcome of glutaminase deficiency in humans; and understand the underlying pathological mechanisms.

DESIGN, SETTING, AND PARTICIPANTS We performed exome sequencing of cases of neurodevelopmental disorders without a clear genetic diagnosis, followed by genetic and bioinformatic evaluation of candidate variants and genes. Establishing pathogenicity of the variants was achieved by measuring metabolites in dried blood spots by a hydrophilic interaction liquid chromatography method coupled with tandem mass spectrometry. The participants are 2 families with a total of 4 children who each had lethal, therapy-refractory early neonatal seizures with status epilepticus and suppression bursts, respiratory insufficiency, simplified gyral structures, diffuse volume loss of the brain, and cerebral edema. Data analysis occurred from October 2017 to June 2018.

MAIN OUTCOMES AND MEASURES Early neonatal epileptic encephalopathy with glutaminase deficiency and lethal outcome.

RESULTS A total of 4 infants from 2 unrelated families, each of whom died less than 40 days after birth, were included. We identified a homozygous frameshift variant p.(Asp232Glufs*2) in GLS in the first family, as well as compound heterozygous variants p. $\left(\mathrm{Gln} 81^{*}\right)$ and p.(Arg272Lys) in GLS in the second family. The GLS gene encodes glutaminase (Enzyme Commission 3.5.1.2), which plays a major role in the conversion of glutamine into glutamate, the main excitatory neurotransmitter of the central nervous system. All 3 variants probably lead to a loss of function and thus glutaminase deficiency. Indeed, glutamine was increased in affected children (available $z$ scores, 3.2 and 11.7). We theorize that the potential reduction of glutamate and the excess of glutamine were a probable cause of the described physiological and structural abnormalities of the central nervous system.

CONCLUSIONS AND RELEVANCE We identified a novel autosomal recessive neurometabolic disorder of loss of function of glutaminase that leads to lethal early neonatal encephalopathy. This inborn error of metabolism underlines the importance of GLS for appropriate glutamine homeostasis and respiratory regulation, signal transduction, and survival.

Author Affiliations: Author affiliations are listed at the end of this article.

Corresponding Author: Rami Jamra, MD, Institute of Human Genetics, University Medical Center, Philipp-Rosenthal-Straße 55 Leipzig 04103, Germany (rami. aboujamra@medizin.uni-leipzig.de). 
$\mathrm{E}$ pileptic encephalopathies are a large and heterogeneous group of disorders. Genetic factors are assumed to be causative in most cases. ${ }^{1-4}$ In outbred populations, frequent causes of severe epileptic encephalopathy are de novo heterozygous genetic variants. ${ }^{5-7}$ However, autosomal recessive inheritance is common, especially for metabolic disorders. ${ }^{8}$ Identification and characterization of genetic causes of neurodevelopmental disorders is essential to enable counselling of relatives regarding prognosis and recurrence risk. Understanding the pathological mechanisms is an essential basic knowledge for developing and enabling personalized and specific treatment.

In this study, we describe pathogenic alterations in the K-type mitochondrial glutaminase (GLS; Enzyme Commission 3.5.1.2) encoded by GLS that is ubiquitously expressed, with a particularly high expression in the brain. ${ }^{9}$ Glutaminase plays a pivotal role in the production of glutamate, the main excitatory neurotransmitter in the central nervous system, including the brain stem respiratory center. ${ }^{10-12}$ In the respiratory center, respiratory volume, frequency, and rhythm are regulated by information from chemoreceptors and mechanoreceptors mediated by glutamatergic signal transduction. ${ }^{13}$ In addition, glutamate induces myelination of axons. It furthermore fuels the mitochondrial citric acid (tricarboxylic acid) cycle through a-ketoglutarate, thereby regulating energy metabolism, which is important for the high energy demands of the brain. ${ }^{14,15}$ Glutamate is produced by GLS from glutamine, an important ammonia detoxifier and a building block of proteins, and a source of other amino acids, purines, and pyrimidines. Here, we describe 4 individuals from 2 families with biallelic GLS loss-of-function variants, who clinically presented with neonatal respiratory failure, status epilepticus with suppression bursts, and early death.

\section{Methods}

\section{Ethical Approval}

All analyses were performed in concordance to the provisions of the German Gene Diagnostic Act (Gendiagnostikgesetz) and the General Data Protection Act (Bundesdatenschutzgesetz). The testing was done as part of routine clinical care. The project was approved by the ethics committee of the University of Leipzig, Germany in accordance with the Declaration of Helsinki. ${ }^{16}$ Written informed consent of all examined individuals or their legal representatives was obtained after advice and information about the risks and benefits of the study was given.

\section{Exome Sequencing}

We performed 2x100bp exome sequencing on a HiSeq4000 platform (Illumina) after library preparation with SureSelectXT (Agilent Genomics) and enrichment with SureSelect All Human Version 6 (60Mb; Agilent Genomics). In one family, we performed single-exome sequencing of 1 affected child (coverage of $\times 10$ at $98.7 \%$ of the targeted sequences). In the other family, we performed trio-exome sequencing; coverage of $\times 10$ was achieved in $98.8 \%$ of targeted sequences in the affected

\section{Key Points}

Question What is the consequence of glutaminase deficiency?

Findings This study of 2 families with 4 affected children used exome sequencing followed by functional analysis to show that biallelic loss-of-function pathogenic variants in the glutaminase gene GLS lead to early neonatal refractory seizures, respiratory failure, structural brain abnormalities and cerebral edema, and death within weeks after birth.

Meaning Based on these results, it is hypothesized that glutaminase deficiency disturbs glutamine-glutamate homeostasis and leads to neonatal lethal epileptic encephalopathy and respiratory insufficiency; this emphasizes its importance for respiratory regulation, neurotransmission, and survival.

infant: $98.7 \%$ in 1 parent and $99.1 \%$ in the other parent. Validation of the findings and segregation of the variants were performed with Sanger sequencing for all available family members.

\section{Variant Prioritization}

Analysis of the raw data was performed using the software Varfeed (Limbus Medical Technologies) and the variants were annotated and prioritized using the software Varvis (Limbus Medical Technologies). To identify previously described variants, we compared our findings with the Human Gene Mutation Database and ClinVar. ${ }^{17,18}$ Candidate variants were prioritized based on phenotype, family history, inheritance, minor allele frequency, effect on protein function, in silico prediction tools, gene and variant attributes, and the published literature.

Blood Spot Analyses and Metabolic Measurements Glutamine and glutamate concentrations were measured in dried blood spots by a hydrophilic interaction liquid chromatography method coupled with tandem mass spectrometry (Xevo TQ; Waters). This method is based on a previously described method for amino acid analysis in plasma, with slight modifications. ${ }^{19}$

\section{Statistical Analysis}

To correct for spontaneous in vitro conversion of glutamine into glutamate, concentrations were converted to $z$ scores based on 10 control blood spots obtained on the same day and stored under the same circumstances. $z$ Scores greater than 2 were considered significant. Data analysis occurred from October 2017 to June 2018.

\section{Results}

\section{Family 1}

One affected infant (Figure 1A) was a child of consanguineous, healthy parents. The infant was born by cesarean section. Apgar scores were 6, 5, and 7 at 1, 5, and 10 minutes, respectively, with limited spontaneous respiration and marked 
Figure 1. Pedigrees of Families and Magnetic Resonance Images of Affected Children

A MRI of infant of family 1

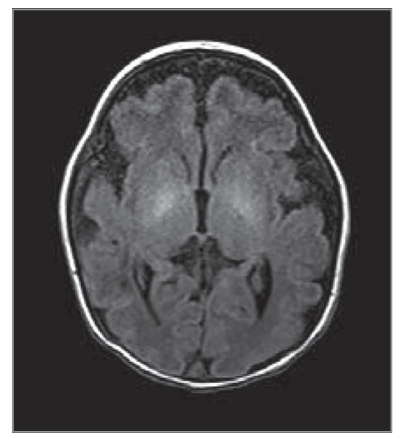

C Sagittal T2-weighted image of infant of family 1

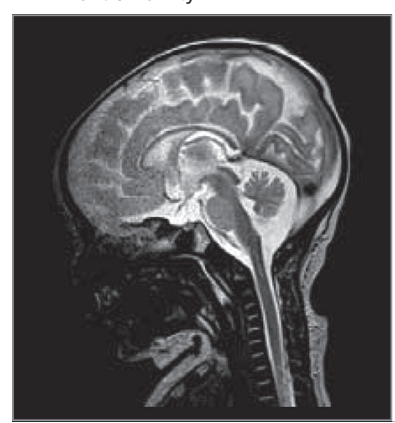

E Trace map of diffusion-weighted image of infant of family 1

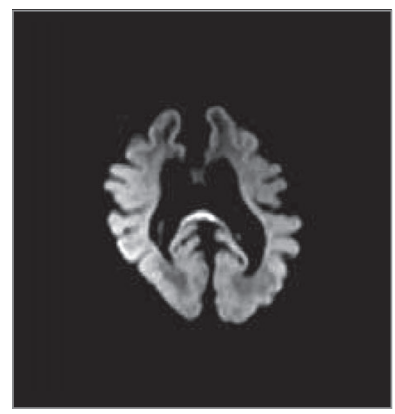

F Axial T1-weighted image of infant of family 2

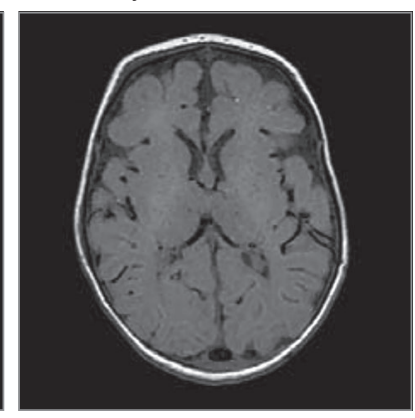

A, A magnetic resonance image (MRI) shows simplified gyral patterns and destruction over time in axial T1 weighted image of the affected infant in family 1 , including an anterior-to-posterior gradient and deep and subcortical white matter involvement on day 1. B, Gliosis and volume loss of the basal ganglia and thalami, as well as a pronounced white matter involvement. C and D, Sagittal T2-weighted images shortly after birth and later, with reduction of an initially normally constructed brainstem, vermis, and corpus callosum, with a prominent cisterna magna also depicted. E, A trace map of a diffusion-weighted image with a high signal at the splenium, pointing to vasogenic edema. F, An axial

T1-weighted image of an affected child of family 2 , with a simplified gyral pattern of the frontal lobes and white matter involvement of the corticospinal tracts at the level of the posterior limb of the internal capsule.

muscular hypotonia. The infant initially improved with shortterm ventilation via facemask and oxygen supplementation. However, shortly after birth, respiration became insufficient. In addition, myoclonic jerks were noted. The infant was transferred to the neonatal intensive care unit and sedated, incu- bated, and artificially ventilated. Within the next few hours, focal seizures intensified and spread and eventually also included tonic-clonic seizures of all limbs. The infant was cardiorespiratory stable on the ventilator. Seizures were refractory to lorazepam, levetiracetam, sodium benzoate, valproic acid, pulse steroid therapy, and a trial of dextromethorphan given on suspicion of nonketotic hyperglycinemia. Temporary remission of seizures was achieved when starting phenobarbital and initiating a 3-day thiopental-induced coma. However, after discontinuation, seizures reoccurred within 1 day. Similarly, a continuous infusion of ketamine was started and led to a seizure-free interval of 2 days, but this medication then lost its effect even after the dose was increased to $5 \mathrm{mg} / \mathrm{kg} / \mathrm{h}$. Physical examinations revealed an inadequate reaction to external stimuli, muscular hypotonia, absence of sucking reflex, and uncoordinated movements. There were no dysmorphic features. Results of the metabolic newborn screening were unremarkable. Repeated attempts to wean the infant from the ventilator were unsuccessful. Electroencephalography revealed long-lasting suppressed activity that was interrupted by short, high-amplitude $\Theta$ activity, meeting the criteria of persistent burst-suppression patterns. Magnetic resonance imaging (MRI) showed a simplified frontal gyral pattern with an anterior-to-posterior gradient and deep and subcortical white matter involvement (Figure 1A). A follow-up MRI later showed gliosis, especially in the frontal deep white matter, caused by brain parenchymal destruction, as well as marked volume loss of the initially normal-appearing basal ganglia, corpus callosum, thalami, brainstem, and vermis, all possibly because of direct destruction and secondary network injury (Figure 1B-E). On a diffusion-weighted magnetic resonance image, extensive vasogenic cerebral edema was seen, especially in the deep white matter and corpus callosum, which was interpreted as being caused by the seizure activity. Therapy was discontinued in agreement with the parents, and the infant died. At that time, the diagnosis remained unknown.

Another infant of the family had died after a similar disease course. A summary of the phenotype is given in the Table.

\section{Family 2}

An affected infant of this family (Figure 1B) was a child of nonconsanguineous, healthy parents. Pregnancy had been largely uneventful until the last month. During delivery at full term, pethidine was administered, and meconium-stained amniotic fluid and a pathological cardiotocography were noticed. Apgar scores were 2, 7, and 7 at 1, 5, and 10 minutes, respectively, with limited spontaneous respiration and marked muscular hypotonia. The infant improved with respiratory support. However, when respiratory support was withheld, the infant exhibited Cheyne-Stokes respiration and was therefore transferred to the intensive care unit. There, the infant was sedated, incubated, and artificially ventilated. Low arterial blood pressure was treated with catecholamine, dopamine, and adrenaline. Additionally, diabetes insipidus was suspected because of high diuresis, for which a trial of desmopressin was administered. At day 2, the infant developed focal seizures, with variably combined asymmetric tonic movements, irregular eye movement, clonus of the eyelid and the upper and the 


\begin{tabular}{|c|c|c|c|c|}
\hline \multirow[b]{2}{*}{ Characteristic } & \multicolumn{2}{|l|}{ Family 1} & \multicolumn{2}{|l|}{ Family 2} \\
\hline & 1 & 2 & 1 & 2 \\
\hline Genomic position (hg19) & Not tested & chr2:191765378 & $\begin{array}{l}\text { chr2:191766752 and } \\
\text { chr2:191746051 }\end{array}$ & $\begin{array}{l}\text { chr2:191766752 and } \\
\text { chr2:191746051 }\end{array}$ \\
\hline $\begin{array}{l}\text { Human Genome Variation } \\
\text { Society DNA reference }\end{array}$ & Not tested & c.695dup & c. $815 \mathrm{G} \rightarrow \mathrm{A} / \mathrm{c} .241 \mathrm{C} \rightarrow \mathrm{T}$ & c. $815 \mathrm{G} \rightarrow \mathrm{A} / \mathrm{c} .241 \mathrm{C} \rightarrow \mathrm{T}$ \\
\hline Protein alteration & Not tested & p.(Asp232Glufs*2) & p.(Arg272Lys)/p.(Gln81*) & p.(Arg272Lys)/p.(Gln81*) \\
\hline Zygosity & Not tested & Homozygous & Compound heterozygous & Compound heterozygous \\
\hline \multicolumn{5}{|l|}{ Length at birth ${ }^{20}$} \\
\hline Length, $\mathrm{cm}$ & Unknown & 49 & 47 & 47 \\
\hline Percentile & Unknown & 25 th & 1st & 1st \\
\hline \multicolumn{5}{|l|}{ Weight at birth ${ }^{20}$} \\
\hline Weight, $g$ & Unknown & 3040 & 2990 & 3000 \\
\hline Percentile & Unknown & $43 r d$ & 8th & 11th \\
\hline \multicolumn{5}{|l|}{$\begin{array}{l}\text { Head circumference at } \\
\text { birth }^{20}\end{array}$} \\
\hline Circumference, cm & Unknown & 36.5 & Unknown & 32 \\
\hline Percentile & Unknown & 90th & Unknown & 1st \\
\hline \multicolumn{5}{|l|}{ Apgar scores } \\
\hline $1 \mathrm{~min}$ & Unknown & 6 & 2 & 4 \\
\hline $5 \mathrm{~min}$ & Unknown & 5 & 7 & 5 \\
\hline $10 \min$ & Unknown & 7 & 7 & 7 \\
\hline Respiratory dysfunction & $\begin{array}{l}\text { Respiratory } \\
\text { insufficiency }\end{array}$ & $\begin{array}{l}\text { Respiratory insufficiency and } \\
\text { ventilation support }\end{array}$ & $\begin{array}{l}\text { Respiratory insufficiency, ventilation } \\
\text { support, and Cheyne-Stokes } \\
\text { respirations when support was } \\
\text { withheld }\end{array}$ & $\begin{array}{l}\text { Respiratory insufficiency, } \\
\text { hypoventilation, apnea, and } \\
\text { ventilation support }\end{array}$ \\
\hline \multicolumn{5}{|l|}{ Seizures } \\
\hline Description & $\begin{array}{l}\text { Similar course to } \\
\text { affected sibling }\end{array}$ & $\begin{array}{l}\text { Focal cerebral seizures within } 10 \\
\text { min after birth }\end{array}$ & $\begin{array}{l}\text { Focal seizures at day } 2 \text {, followed by } \\
\text { variably combined asymmetric tonic } \\
\text { movements, irregular eye movement, } \\
\text { clonus of the eyelid and the upper and } \\
\text { the lower extremities, and single } \\
\text { myoclonic jerks }\end{array}$ & $\begin{array}{l}\text { Myoclonic seizures of the mouth } \\
\text { at day } 1\end{array}$ \\
\hline Response to therapy & $\begin{array}{l}\text { Similar to } \\
\text { affected sibling }\end{array}$ & Refractory & Refractory & Refractory \\
\hline Muscular tonus & Unknown & Muscular hypotonia & Muscular hypotonia & Muscular hypotonia \\
\hline $\begin{array}{l}\text { Electroencephalographic } \\
\text { results }\end{array}$ & Unknown & Burst-suppression patterns & $\begin{array}{l}\text { Burst-suppression patterns, ictal } \\
\text { pattern: variable focal onset and } \\
\text { variable morphologic features, often } \\
\text { superimposed by rhythmic } \alpha / \beta \\
\text { activity }\end{array}$ & $\begin{array}{l}\text { Burst-suppression patterns with } \\
\text { generalized rhythmical } \\
\text { discharges }\end{array}$ \\
\hline \multicolumn{5}{|l|}{$\begin{array}{l}\text { Brain magnetic resonance } \\
\text { imaging }\end{array}$} \\
\hline $\begin{array}{l}\text { Time of examination, days } \\
\text { postbirth }\end{array}$ & Unknown & 0 and 30 & 3 & 3 \\
\hline Results & Unknown & $\begin{array}{l}\text { At birth, simplified frontal gyral } \\
\text { pattern with an anterior to } \\
\text { posterior gradient and deep and } \\
\text { subcortical white matter } \\
\text { involvement; on follow-up, gliosis, } \\
\text { volume loss of the initially normal } \\
\text { appearing basal ganglia, corpus } \\
\text { callosum, thalami, brain stem and } \\
\text { vermis, and vasogenic cerebral } \\
\text { edema }\end{array}$ & $\begin{array}{l}\text { Simplified gyral pattern of the frontal } \\
\text { lobes and white matter involvement }\end{array}$ & $\begin{array}{l}\text { Severe demyelination; calcium } \\
\text { spots and recess of the fibers in } \\
\text { the subcortical white matter }\end{array}$ \\
\hline Dysmorphic features & Unknown & No & No & No \\
\hline Medications administered & Unknown & $\begin{array}{l}\text { Sterofundin, hydrocortisone, } \\
\text { ampicillin, cefotaxim, tobramycin, } \\
\text { aciclovir, lorazepam, } \\
\text { levetiracetame, phenobarbital, } \\
\text { thiopental, vitamin B-6, pyridoxal } 5 \\
\text { phosphate, calciumfolinate, } \\
\text { ketamine, vigabatrin, steroid, } \\
\text { lacosamid, and valproic acid }\end{array}$ & $\begin{array}{l}\text { Clamoxyl, garamycin, dopamine, } \\
\text { adrenaline, desmopressin, } \\
\text { phenobarbital, phenytoin, pyridoxine, } \\
\text { midazolam, and topiramate }\end{array}$ & $\begin{array}{l}\text { Levetiracetam, phenobarbital, } \\
\text { vigabatrin, vitamin B-6, and } \\
\text { phenytoin }\end{array}$ \\
\hline
\end{tabular}

Abbreviations: EEG, electroencephalogram; MRI, magnetic resonance imaging.

a NM_001256310.1 
lower extremities, and myoclonic jerks. Electroencephalography revealed long-lasting suppressed activity that was interrupted by short, high-amplitude $\Theta$ activity, a pattern consistent with suppression bursts. Seizures were refractory to phenobarbital, phenytoin, pyridoxine, midazolam, and topiramate. A physical examination revealed muscular hypotonia with absence of movements against gravity and absence of reflexes. There were no dysmorphic features. An MRI of the brain revealed a simplified gyral pattern of the frontal lobes and white matter involvement (Figure $1 \mathrm{~F}$ ), similar to that of the other affected infants. Treatment was stopped, and the infant died. The diagnosis remained unknown.

Another infant in the family showed a similar clinical presentation of neonatal respiratory failure and status epilepticus with suppression bursts. On delivery, the infant had no spontaneous respiration, and Apgar scores were 4, 5, and 7 at 1, 5, and 10 minutes. Respiratory support improved circulation, but hypoventilation and apnea persisted. Within hours, myoclonic seizures were noted with a burst-suppression pattern on electroencephalography, which failed to respond to various antiepileptic drugs. An MRI of the brain revealed a simplified gyral pattern, particularly in the frontal lobes. The infant died after treatment was discontinued. The Table presents a summary of the phenotype.

\section{Genetic Results}

Whole-exome sequencing (WES) revealed in 1 infant in family 1 a homozygous frameshift variant in GLS (NM_001256310.1; chr2:191765378, c.695dup, p.[Asp232Glufs*2]). Sanger sequencing confirmed the variant, and both parents are heterozygous. There was no material available from the other affected infant.

In family 2, trio WES revealed compound heterozygous variants in GLS: NM_001256310.1; chr2:191746051, c.241C $\rightarrow$ T, and p.(Gln81*) inherited from 1 parent and chr2:191766752, c.815G $\rightarrow$ A, and p.(Arg272Lys) from the other parent. Sanger sequencing confirmed the variants, and each parent was found to be heterozygous for 1 of the variants. Also, we found that 3 of 4 healthy children in the family were heterozygous for 1 variant, while a fourth was homozygous for the wild type.

All 3 variants were absent from all publicly available databases, including GnomAD (last accessed March 8, 2018). ${ }^{21}$ The truncating variants probably lead to RNA nonsensemediated decay. ${ }^{22}$ In any case, translation would not result in a catalytically competent protein; Arg272 is conserved across evolution from lampreys to vertebrates (Figure 2A), and in silico prediction tools like MutationTaster (MutationTaster probability value, 0.999 on a scale of 0 to 1 ), PolyPhen-2 (score, 0.995 on a scale of 0 to 1), and Combined Annotation Dependent Depletion (raw Phil's Read Editor [PHRED] score [University of Washington Genome Center], 34 on a scale of 1 to 40) suggest a pathogenic outcome of the variant. ${ }^{25-27}$ Available structural information ${ }^{28}$ suggests that Arg272 plays a role in stabilization of the protein fold and may thereby reduce the amount of active GLS (Figure 2B and Figure 2C).

Metabolic Assay

To confirm loss of function of GLS as a consequence of the genetic variants, a mass spectrometry-based method was devel- oped to measure glutamine and glutamate in stored Guthrie cards from the newborn period of all of the children of family 2 , parallel to segregation analyses. Spontaneous in vitro conversion of glutamine into glutamate during storage was observed and corrected by comparing with control blood spots obtained on the same day and stored under the same conditions. Glutamine levels were significantly increased in the affected individuals ( $z$ scores $=3.2$ and 11.7) compared with healthy control neonates ( $z$ scores of siblings in family $2: 0.5$, $0.4,2.0$, and 0.2), underlining GLS loss of function (Figure 2D and Figure 2E). Notably, glutamine was borderline elevated in 1 sibling in family $2(\mathrm{z}=2.0)$, but not in the other siblings, including a sibling sharing the same genotype. Glutamate levels, which remained relatively stable during storage, did not differ between the affected individuals and control participants ( $z$ scores $=0.7$ and -0.8 ; Figure $2 \mathrm{~F}$ and Figure $2 \mathrm{G}$ ); $z$ scores of siblings in family 2 were $-0.7,-0.5,-1.9$, and -0.6 .

\section{Discussion}

We describe 4 children in 2 unrelated families with overlapping phenotypes of lethal neonatal-onset respiratory failure and refractory suppression-burst epileptic encephalopathy. While there were no obvious malformations or organic anomalies, brain MRIs within days of birth showed a simplified gyral pattern with an anterior-to-posterior gradient and deep and subcortical white matter involvement. Genetic analyses revealed a homozygous truncating variant of GLS in family 1 ; in family 2 , there were 2 compound heterozygous variants, a truncating and a missense variant, in GLS. Molecular modeling suggests that the missense variant influences GLS enzyme stability and results in a loss of function. In support of this concept, metabolic analysis on dried blood spots obtained from the newborn screening revealed increased glutamine levels in both affected children of family 2 . The increase of glutamine levels in a healthy sibling was borderline ( $z$ score $=2$ ) and thus much less than 2 affected siblings ( $z$ scores $=11.7$ and 3.2, respectively). This mild elevation of glutamine may be because of technical artifacts or to a minor influence of the mutation on the biochemical values but not on the clinical presentation. Similar phenomena are observed in other metabolic disorders, such as phenylketonuria. ${ }^{29}$

The highly overlapping phenotype of the affected children in both families, as well as the comparable genetic findings, implicate a biallelic loss-of-function variants in GLS that leads to a novel metabolic disorder of early neonatal, refractory, and lethal epileptic encephalopathy.

The GLS loss of function seems to have profound consequences for both construction and maintenance of brain structures. Although the glutamate levels in the dried blood spots were normal, this does not exclude decreased glutamate levels in the brain, as has been shown in knockout mouse model. ${ }^{30}$ The GLS gene is highly expressed in the brain and has a pivotal role in creating glutamate abundance in the brain, contrary to the systemic circulation, in which glutamine is the most abundant amino acid. ${ }^{31,32}$ 
Figure 2. Molecular Modeling of Missense Variant in GLS and Glutamine and Glutamate Analyses in Guthrie Cards of Family 2

A Conservation of Arg272 per multiple sequence alignment

\begin{tabular}{|c|c|c|c|c|c|c|c|c|c|c|c|}
\hline & \multicolumn{2}{|c|}{191.766 .745} & \multicolumn{4}{|c|}{191.766 .750} & \multicolumn{2}{|c|}{ Arg272 } & \multicolumn{3}{|c|}{ 191.766.755 } \\
\hline & A & $T$ & $\mathbf{G}$ & G & A & C & A & $\mathbf{G}$ & G & $\mathrm{T}$ & A \\
\hline GLS & & & & & & & & & & & \\
\hline Human & D & & & G & & & Q & $\mathrm{R}$ & G & $T$ & A \\
\hline Rhesus & D & & & G & & & Q & $\mathrm{R}$ & G & $T$ & $A$ \\
\hline Mouse & D & & & G & & & Q & $\mathrm{R}$ & G & $T$ & A \\
\hline Dog & D & & & G & & & Q & $\mathrm{R}$ & G & $T$ & G \\
\hline Elephant & D & & & G & & & Q & $\mathrm{R}$ & G & $T$ & $A$ \\
\hline Chicken & D & & & G & & & Q & $\mathrm{R}$ & G & $T$ & A \\
\hline $\mathrm{X}$ tropicalis & D & & & G & & & Q & $\mathrm{R}$ & G & $T$ & A \\
\hline Zebrafish & D & & & G & & & Q & $\mathrm{R}$ & G & $T$ & A \\
\hline Lamprey & D & & & G & & & Q & $\mathrm{R}$ & G & $T$ & G \\
\hline
\end{tabular}

B Structure of GLS

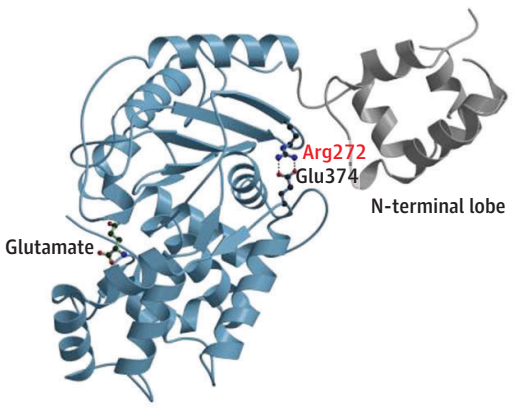

D Concentration of glutamine in Guthrie cards, family 2

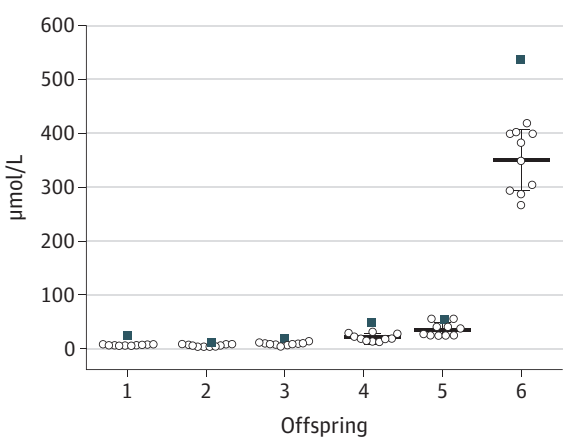

F z Scores of glutamine in Guthrie cards, family 2

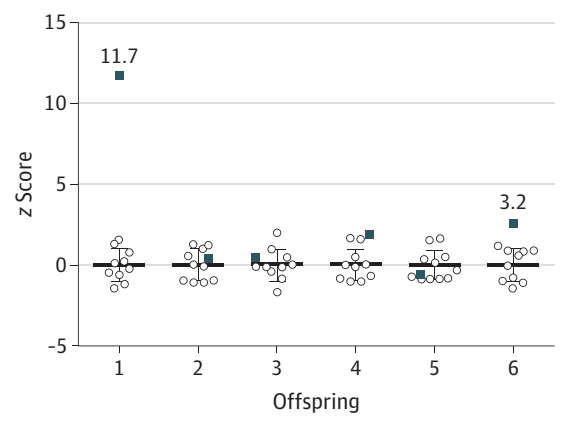

C Structure of GLS, ball-and-stick representation

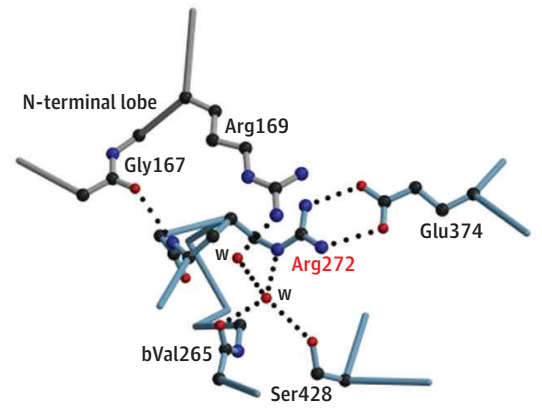

E Concentration of glutamate in Guthrie cards, family 2

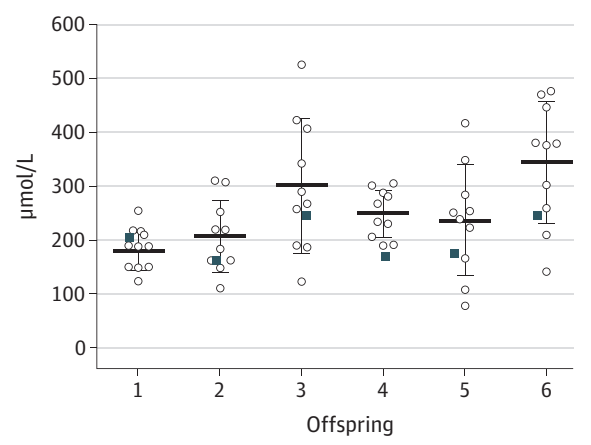

G z Scores of glutamate in Guthrie cards, family 2

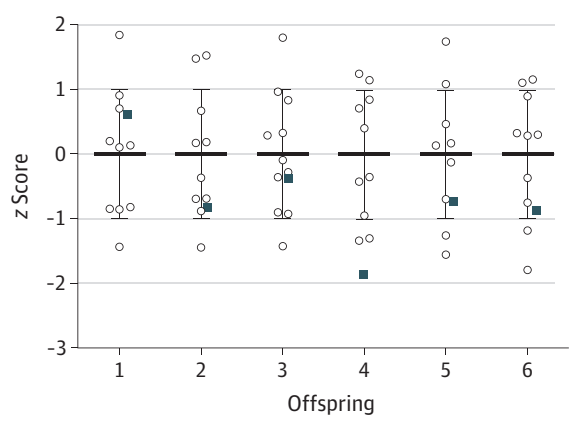

A, Multiple sequence alignment reveals conservation of Arg272 (marked red) throughout evolution across several species (https:// genome.ucsc.edu; human hg19 [Genome Reference Consortium human build 37]). B, Structure of GLS including the $\mathrm{N}$-terminal loop (gray), based on pdb entry 3ss3. C, Glutamate (green) taken from pdb entry $3 s s 5$ to indicate the location of the active site, with Arg272 and Glu374 shown and a detailed view of the environment of Arg272. The backbone amid Arg272 is engaged in a hydrogen bond with Gly167 and oriented parallel to the side chain of Arg169, both localized in the $\mathrm{N}$-terminal lobe with water. Parts B and $\mathrm{C}$ were generated with moscript and raster 3D. ${ }^{23,24}$ Concentration of glutamine (D) and glutamate (E) in Guthrie cards and $z$ scores of glutamine $(F)$ and glutamate $(G)$ in Guthrie cards of the children of family 2 (black squares), calculated from the mean and standard deviation of 10 control participants for each measurement obtained at the same day and stored under the same conditions (white dots) and expressed as $z$ scores.
Brain MRIs of the affected children of both families showed simplified gyral patterns. An affected child of family 1 was followed up after 1 month, revealing cerebral vasogenic edema and destruction of initially normal appearing basal ganglia, corpus callosum, thalami, brain stem and vermis. Cerebral edema might be because of glutamine accumulation, which is associated with cerebral osmotic, thus cellular edema. ${ }^{33,34}$ However, the observed vasogenic (rather than cellular) edema in the white matter is also a known consequence of ongoing epileptic activity. ${ }^{35}$ Subsequent damage of the white matter tracts 
results in gliosis formation, which was seen in this infant in the follow-up MRI. ${ }^{36}$

Decreased glutamate levels may also contribute to the pathogenic brain morphology. As glutamate induces myelin synthesis, decreased glutamate levels are likely to result in white matter involvement, probably explaining the unmyelinated corticospinal tract at the level of the thalami seen in the affected children. ${ }^{37}$

The normal glutamate levels in dried blood spots might be explained by uptake from the diet and the numerous enzymes that metabolize glutamate. ${ }^{36}$ These enzymes might have corrected the glutamate deficiency created by GLS loss of function, pointing to the importance of maintained glutamate levels.

The GLS loss of function has severe consequences on brain physiology. Glutamate facilitates signal transduction in the brainstem respiratory center, where respiratory volume, frequency, and rhythm are regulated immediately after birth. ${ }^{13}$ Respiratory dysfunction in the affected children is therefore likely a consequence of GLS loss of function. A GLS knockout mouse model supports this observation, because these mice also develop respiratory dysfunction. ${ }^{30}$ This mouse model shows that GLS deficiency leads to reduced neuronal glutamate release, reduced chemosensitivity to carbon dioxide, hypoventilation, and a decreased tidal volume. This is in line with the respiratory phenotype of the affected children, which is characterized by hypoventilation, apnea, and Cheyne-Stokes respiration. It cannot be fully excluded that respiratory dysfunction is secondary to epilepsy. However, in the knockout mouse model, respiratory dysfunction was observed, and the authors did not report seizures. ${ }^{30}$

The observed refractory epilepsy of the affected children may be the consequence of glutamate deficiency caused by GLS loss of function. Disturbed glutamine-glutamate shuttling is a known cause of epilepsy. ${ }^{38,39}$ Another known mechanism of epilepsy is mitochondrial dysfunction via energy depletion. ${ }^{40}$ Glutamate deficiency likely leads to a decreased tricarboxylic acid cycle flux because there is less a-ketoglutarate supply, and it might therefore lead to mitochondrial dysfunction. Interestingly, another inborn error of glutamate metabolism with mitochondrial dysfunction has been associated with neonatal epileptic encephalopathy and suppression bursts. This defect is caused by biallelic variants in mitochondrial glutamate carrier 1 (GC1, encoded by SLC25A22), which lead to reduced mitochondrial glutamate transport and oxidation. ${ }^{41,42}$

Interestingly, patients with different defects in the glutamate-metabolizing pathway show clinical parallels and differences. Patients with a SLC25A22 defect present similarly with very early neonatal severe intractable myoclonic seizures, muscular hypotonia, and epileptic encephalopathy. ${ }^{41,42}$ There is no known effective treatment, and children with this condition either die within 1 to 2 years after birth or survive in a persistent vegetative state. Deficiency of glutamine syn- thetase (Enzyme Commission 6.3.1.2), which performs the reverse reaction of GLS, has been reported in 3 individuals. As expected, these patients presented biochemically with decreased glutamine concentrations, rather than increased concentrations, in the brain, plasma, and urine. ${ }^{39,43}$ Additionally, they exhibited hyperammonemia, which was absent in our patients. Nevertheless, despite the contrasting biochemical phenotype, these patients also exhibited neonatal encephalopathy, seizures, respiratory failure, and early death. However, glutamine synthetase-deficient individuals did not show suppression bursts on electroencephalographic examination.

Interestingly, in all described disorders affecting glutamate metabolism, disturbed glutamate homeostasis leads to a severe neurological phenotype. Under physiological circumstances, homeostasis of glutamine and glutamate in the brain is strictly regulated by the glutamine-glutamate shuttle. Glutamate is excreted by neurons into the synaptic cleft as a neurotransmitter and absorbed by astrocytes, where it is converted into glutamine by glutamine synthetase. Glutamine is then transported toward neurons and again converted into glutamate by glutaminase to restart signal transduction. ${ }^{38,44}$ It is therefore not surprising that disturbed glutamate homeostasis, either by defective synthesis in both directions or by defective transport, is detrimental for neurological functioning.

This inborn error of metabolism underlines the importance of GLS for appropriate glutamine-glutamate homeostasis and respiratory regulation, neurotransmission, and survival. It is quite possible that different variants in GLS may lead to milder phenotypes (eg, ones caused by hypomorphic mutations). Independent reporting of additional affected individuals would delineate the phenotype and its correlation with the genotype.

\section{Limitations}

This study describes the findings of 2 families and 4 affected individuals. Further cases are necessary to further delineate the phenotype and describe its full spectrum. The functional analyses in this study were limited to dry blood spots. Analyses in cell lines may lead to deviating findings and are necessary to better understand the pathological mechanisms and suggest therapeutic approaches.

\section{Conclusions}

In conclusion, we describe a novel autosomal recessive cause of lethal neonatal-onset respiratory failure and epileptic encephalopathy caused by biallelic loss-of-function variants in GLS. We describe a novel autosomal recessive disorder of lethal neonatal-onset respiratory failure and epileptic encephalopathy caused by biallelic loss-of-function variants in GLS.
ARTICLE INFORMATION

Accepted for Publication: July 6, 2018.

Published Online: December 21, 2018. doi:10.1001/jamaneurol.2018.2941
Author Affiliations: Department of Genetics, University Medical Center Utrecht, Utrecht University, Utrecht, the Netherlands (Rumping, Schiebergen-Bronkhorst, Prinsen, Jans, Verhoeven-Duif); Center for Molecular Medicine,
University Medical Center Utrecht, Utrecht University, Utrecht, the Netherlands (Rumping, Jans, Verhoeven-Duif, van Hasselt); Department of Pediatrics, University Medical Center Utrecht, Utrecht University, Utrecht, the Netherlands 
(Rumping, Houwen); Institute of Human Genetics, University Medical Center Leipzig, Leipzig, Germany (Büttner, Lemke, Jamra); Department of Neuropediatrics, Development and Rehabilitation, Children's Hospital of Eastern Switzerland, St Gallen, Switzerland (Maier); Center for Molecular Medicine, Department of Molecular Cancer Research, University Medical Center Utrecht, Utrecht, the Netherlands (Rehmann, Zwartkruis); Oncode Institute, Utrecht, the Netherlands (Rehmann, Zwartkruis); Expertise Centre for Structural Biology, University Medical Center Utrecht, Utrecht University, Utrecht, the Netherlands (Rehmann); Department of Radiology, University Medical Center Utrecht, Utrecht University, Utrecht, the Netherlands (Lequin); Division for Children and Adolescents, Evangelical Hospital Oberhausen, Oberhausen, Germany (Schlump); Department of Child Neurology, University Children's Hospital, Zurich, Switzerland (Schmitt); Department of Pediatric Intensive Care and Neonatology, Children's Hospital of Eastern Switzerland, St Gallen, Switzerland (Losa); Swiss Newborn Screening Laboratory and Children`s Research Center, University Children's Hospital Zurich, Zurich, Switzerland (Fingerhut).

Author Contributions: Drs van Hasselt and Jamra had full access to all of the data in the study and take responsibility for the integrity of the data and the accuracy of the data analysis. Dr Rumping and Mr Büttner contributed equally to this article as co-first authors, and Drs van Hasselt and Jamra contributed equally to this article as co-last authors.

Concept and design: Rumping, Büttner, Schiebergen-Bronkhorst, Prinsen, Lemke, van Hasselt, Jamra.

Acquisition, analysis, or interpretation of data: Rumping, Büttner, Maier, Rehmann, Lequin, Schlump, Schmitt, Schiebergen-Bronkhorst, Prinsen, Losa, Fingerhut, Zwartkruis, Houwen, Jans, Verhoeven-Duif, van Hasselt, Jamra.

Drafting of the manuscript: Rumping, Büttner, Schiebergen-Bronkhorst, Prinsen, Verhoeven-Duif, van Hasselt, Jamra.

Critical revision of the manuscript for important intellectual content: All authors.

Statistical analysis: Rumping, Büttner, Jamra. Obtained funding: Büttner.

Administrative, technical, or material support: Rumping, Büttner, Schlump,

Schiebergen-Bronkhorst, Prinsen, Fingerhut, Lemke, Zwartkruis, Jans, Verhoeven-Duif, Jamra. Supervision: Lequin, Schlump, Prinsen, Lemke, Houwen, Jans, Verhoeven-Duif, van Hasselt, Jamra. Conflict of Interest Disclosures: None reported.

\section{REFERENCES}

1. Lemke JR, Riesch E, Scheurenbrand T, et al. Targeted next generation sequencing as a diagnostic tool in epileptic disorders. Epilepsia. 2012;53(8):1387-1398. doi:10.1111/j.1528-1167.2012. 03516.x

2. McTague A, Howell KB, Cross JH, Kurian MA Scheffer IE. The genetic landscape of the epileptic encephalopathies of infancy and childhood. Lancet Neurol. 2016;15(3):304-316. doi:10.1016/S14744422(15)00250-1

3. von Deimling M, Helbig I, Marsh ED. Epileptic encephalopathies-clinical syndromes and pathophysiological concepts. Curr Neurol Neurosci Rep. 2017;17(2):10. doi:10.1007/s11910-017-0720-7
4. Olson HE, Kelly M, LaCoursiere CM, et al. Genetics and genotype-phenotype correlations in early onset epileptic encephalopathy with burst suppression. Ann Neurol. 2017;81(3):419-429. doi: 10.1002/ana.24883

5. Rauch A, Wieczorek D, Graf E, et al. Range of genetic mutations associated with severe non-syndromic sporadic intellectual disability: an exome sequencing study. Lancet. 2012;380(9854): 1674-1682. doi:10.1016/S0140-6736(12)61480-9

6. de Ligt J, Willemsen MH, van Bon BWM, et al. Diagnostic exome sequencing in persons with severe intellectual disability. N Engl J Med. 2012;367 (20):1921-1929. doi:10.1056/NEJMoa1206524

7. Heyne HO, Singh T, Stamberger $\mathrm{H}$, et al; EuroEPINOMICS RES Consortium. De novo variants in neurodevelopmental disorders with epilepsy. Nat Genet. 2018;50(7):1048-1053. doi:10.1038/ s41588-018-0143-7

8. van Karnebeek CDM, Houben RFA, Lafek M, Giannasi W, Stockler S. The treatable intellectual disability APP www.treatable-id.org: a digital tool to enhance diagnosis \& care for rare diseases. Orphanet J Rare Dis. 2012;7:47. doi:10.1186/17501172-7-47

9. The Broad Institute of MIT and Harvard. GTEx Portal. https://www.gtexportal.org. Accessed March 20, 2018.

10. Curthoys NP, Watford M. Regulation of glutaminase activity and glutamine metabolism. Annu Rev Nutr. 1995;15:133-159. doi:10.1146/ annurev.nu.15.070195.001025

11. Curtis DR, Phillis JW, Watkins JC. The chemical excitation of spinal neurones by certain acidic amino acids. J Physiol. 1960;150(3):656-682. doi: 10.1113/jphysiol.1960.sp006410

12. Rowley NM, Madsen KK, Schousboe A, Steve White H. Glutamate and GABA synthesis, release, transport and metabolism as targets for seizure control. Neurochem Int. 2012;61(4):546-558. doi: 10.1016/j.neuint.2012.02.013

13. Kolesnikova EÉ. Role of glutamate and GABA in mechanisms underlying respiratory control. Neurophysiology. 2011;42(4):349-360. doi:10.1007/ s11062-011-9162-z

14. Mount CW, Monje M. Wrapped to adapt: experience-dependent myelination. Neuron. 2017; 95(4):743-756. doi:10.1016/j.neuron.2017.07.009

15. Nedergaard M, Takano T, Hansen AJ. Beyond the role of glutamate as a neurotransmitter. Nat Rev Neurosci. 2002;3(9):748-755. doi:10.1038/nrn916

16. World Medical Association. World Medical Association Declaration of Helsinki: ethical principles for medical research involving human subjects. JAMA. 2013;310(20):2191-2194. doi:10. 1001/jama.2013.281053

17. Stenson PD, Ball EV, Mort M, et al. Human gene mutation database (HGMD): 2003 update. https://portal.biobase-international.com/hgmd. Published 2003. Accessed March 20, 2018.

18. Landrum MJ, Lee JM, Riley GR, et al. ClinVar: public archive of relationships among sequence variation and human phenotype. Nucleic Acids Res. 2014;42(database issue):D980-D985. doi:10.1093/ nar/gkt1113

19. Prinsen HCMT, Schiebergen-Bronkhorst BGM, Roeleveld MW, et al. Rapid quantification of underivatized amino acids in plasma by hydrophilic interaction liquid chromatography (HILIC) coupled with tandem mass-spectrometry. J Inherit Metab Dis. 2016;39(5):651-660. doi:10.1007/s10545016-9935-z

20. Voigt M, Fusch C, Olbertz D, et al. Analyse des Neugeborenenkollektivs der Bundesrepublik Deutschland. Geburtshilfe Frauenheilkd. 2006;66 (10):956-970. doi:10.1055/s-2006-924458

21. Lek M, Karczewski KJ, Minikel EV, et al; Exome Aggregation Consortium. Analysis of protein-coding genetic variation in 60,706 humans. Nature. 2016;536(7616):285-291. doi:10.1038/ nature19057

22. Lykke-Andersen S, Jensen TH. Nonsense-mediated mRNA decay: an intricate machinery that shapes transcriptomes. Nat Rev Mol Cell Biol. 2015;16(11):665-677. doi:10.1038/nrm4063

23. Kraulis PJ. MOLSCRIPT: a program to produce both detailed and schematic plots of protein structures. J Appl Cryst. 1991;24:946-950. Journal of Applied Crystallography. doi:10.1107/ SO021889891004399

24. Merritt EA, Murphy ME. Raster3D version 2.0: a program for photorealistic molecular graphics. Acta Crystallogr D Biol Crystallogr. 1994;50(pt 6) 869-873. doi:10.1107/S0907444994006396

25. Schwarz JM, Cooper DN, Schuelke M, Seelow D. MutationTaster2: mutation prediction for the deep-sequencing age. Nat Methods. 2014;11(4):361362. doi: $10.1038 /$ nmeth. 2890

26. Adzhubei IA, Schmidt S, Peshkin L, et al. A method and server for predicting damaging missense mutations. Nat Methods. 2010;7(4):248249. doi:10.1038/nmeth0410-248

27. Kircher M, Witten DM, Jain P, O'Roak BJ, Cooper GM, Shendure J. A general framework for estimating the relative pathogenicity of human genetic variants. Nat Genet. 2014;46(3):310-315. doi:10.1038/ng.2892

28. Cassago A, Ferreira APS, Ferreira IM, et al. Mitochondrial localization and structure-based phosphate activation mechanism of glutaminase $C$ with implications for cancer metabolism. Proc Natl Acad Sci U S A. 2012;109(4):1092-1097. doi:10.1073/ pnas.1112495109

29. Blitzer MG, Bailey-Wilson JE, Shapira E.

Discrimination of heterozygotes for

phenylketonuria, persistent hyperphenylalaninemia and controls by phenylalanine loading. Clin Chim Acta. 1986;161(3):347-352. doi:10.1016/0009-8981(86) 90020-3

30. Masson J, Darmon M, Conjard A, et al. Mice lacking brain/kidney phosphate-activated glutaminase have impaired glutamatergic synaptic transmission, altered breathing, disorganized goal-directed behavior and die shortly after birth. J Neurosci. 2006;26(17):4660-4671. doi:10.1523/ JNEUROSCI.4241-05.2006

31. Newsholme P, Procopio J, Lima MMR, Pithon-Curi TC, Curi R. Glutamine and glutamate-their central role in cell metabolism and function. Cell Biochem Funct. 2003;21(1):1-9. doi: 10.1002/cbf.1003

32. Bode BP. Recent molecular advances in mammalian glutamine transport. J Nutr. 2001;131 (9)(suppl):2475S-2485S. doi:10.1093/jn/131.9.2475S

33. Takahashi H, Koehler RC, Brusilow SW, Traystman RJ. Inhibition of brain glutamine accumulation prevents cerebral edema in 
hyperammonemic rats. Am J Physiol. 1991;261(3 pt 2): $\mathrm{H} 825-\mathrm{H} 829$.

34. Butterworth RF. Pathophysiology of brain dysfunction in hyperammonemic syndromes: the many faces of glutamine. Mol Genet Metab. 2014; 113(1-2):113-117. doi:10.1016/j.ymgme.2014.06.003

35. Hong K-S, Cho Y-J, Lee SK, Jeong S-W, Kim WK Oh EJ. Diffusion changes suggesting predominant vasogenic oedema during partial status epilepticus. Seizure. 2004;13(5):317-321. doi:10.1016/j.seizure. 2003.08.004

36. Yelamanchi SD, Jayaram S, Thomas JK, et al. A pathway map of glutamate metabolism. J Cell Commun Signal. 2016;10(1):69-75. doi:10.1007/ s12079-015-0315-5

37. Lundgaard I, Luzhynskaya A, Stockley JH, et al; Charles Ffrench-Constant. Neuregulin and BDNF induce a switch to NMDA receptor-dependent myelination by oligodendrocytes. PLOS Biol. 2013;11 (12):e1001743. doi:10.1371/journal.pbio.1001743

38. Barker-Haliski M, White HS. Glutamatergic mechanisms associated with seizures and epilepsy. Cold Spring Harb Perspect Med. 2015;5(8):aO22863. doi:10.1101/cshperspect.a022863

39. Spodenkiewicz M, Diez-Fernandez C Rüfenacht V, Gemperle-Britschgi C, Häberle J. Minireview on glutamine synthetase deficiency, an ultra-rare inborn error of amino acid biosynthesis. Biology (Basel). 2016;5(4):E40.

40. Rahman S. Pathophysiology of mitochondrial disease causing epilepsy and status epilepticus. Epilepsy Behav. 2015;49:71-75. doi:10.1016/j.yebeh. 2015.05.003

41. Molinari F, Kaminska A, Fiermonte G, et al. Mutations in the mitochondrial glutamate carrier
SLC25A22 in neonatal epileptic encephalopathy with suppression bursts. Clin Genet. 2009;76(2): 188-194. doi:10.1111/j.1399-0004.2009.01236.x

42. Molinari F, Raas-Rothschild $A$, Rio $M$, et al. Impaired mitochondrial glutamate transport in autosomal recessive neonatal myoclonic epilepsy. Am J Hum Genet. 2005;76(2):334-339. doi:10. 1086/427564

43. Häussinger D, Schliess F. Glutamine metabolism and signaling in the liver. Front Biosci. 2007;12:371-391. doi:10.2741/2070

44. Bak LK, Schousboe A, Waagepetersen HS. The glutamate/GABA-glutamine cycle: aspects of transport, neurotransmitter homeostasis and ammonia transfer. J Neurochem. 2006;98(3):641653. doi:10.1111/j.1471-4159.2006.03913.x 